\title{
Explore the Role of Cultures in Influencing the Dynamics of Counseling among the First Years in Institutions of Higher Learning. The Case of 2012-2014 Freshmen Study in Two Former Black Universities
}

\author{
Prof. S. M Kang'ethe \\ University of Fort Hare, Department of Social Work and Social Development, \\ Box X1314, Alice. 5700, South Africa \\ Email: skangethe@ufh.ac.za \\ Dr Patricia Muhuro \\ Senior Consultant, Teaching and Learning Centre, University of Fort Hare \\ Email: pmuhuro@ufh.ac.za
}

Doi:10.5901/mjss.2014.v5n27p1050

\begin{abstract}
Despite the abundance of counseling centres in most higher education institutions as a strategy to assist students who are experiencing social-psychological problems that inhibit their learning and retention, there seem to be concern that most of the students do not make use of this service. The aim of the study was to seek the role of culture in influencing students' consumption of counseling services. The study adopted mixed methods design employing qualitative and qualitative approaches. Specifically the study used a case study design and mini survey. However the qualitative approach was more dominant. An interview guide and a questionnaire as research instruments were also used. Document analysis, focus group discussions and interviews gathered qualitative data while a questionnaire was used to gather quantitative data. The sample consisted of 220 conveniently sampled first year students drawn from two former black Universities. These students were largely coming from rural and semi-urban parts of South Africa. Findings indicate that culture was more influential to students' dispositions to use counseling services. It emerged that more than half of the first year students who participated in the study had not used counselling services even though they were aware of its existence. Reasons for non use included stigma from fellow students who associated counseling with failure for one to solve their own problems. Also viewed from African cultural lenses, students felt that counselors were not members of the clan or immediate family for one to share their problems. These findings therefore support the view that African traditional cultures may not adequately fit into the western centric counseling counseling services. The paper recommends that counselling co-ordinators strengthen their marketing of counselling services to allay the fears and distrust students have. Also culturally sensitive counselling procedures may be required to build confidence among those students who make use of the services.
\end{abstract}

Keywords: Cultural beliefs, empathy, upholding integrity, cultural norms, gender, freshmen, trust, mimicking

\section{Problem Statement}

Although counseling as an intervention to address students' social, psychological and emotional challenges is provided in many institutions of higher learning, apparently not all the freshmen take advantage of it. This could be because of the challenges presented by cultural diversity making some freshmen to ignore, disregard or develop apathy towards it. There are concerns and possibilities that different aspects of culture may impede the freshmen to demean the opportunity and therefore make the program redundant. It is therefore critical that an empirical investigation is made to tap the opinions, attitudes, and insights of the freshmen as pertains to the role of cultures in influencing the state of counseling in a few institutions of higher learning. The results could offer an opportunity to market, advocate and lobby for the freshmen to dilute aspects of cultures that dissuade them from consuming the services of counseling.

\section{Background and Introduction}

Perhaps when considering the behavior of people towards consuming help seeking service or intervention, it is critical to understand how diversity influences attitudes, behaviours and views among different population groups. Research seems to show that diversity issues such as personality, language and cultural beliefs influence people's inclination to seek 
counselling services (Dryden \& Reeves, 2008). Counseling is a process by which a person experiencing a stressing or a stressful situation holds a discussion with a professional in order to get insight on how to solve their challenge (Rogers, 1971, Means \& Thorne, 2007). Even though sometimes other people refer a person for counselling, especially when they realize that the relationships, responsibility and health of that individual are at risk (Morrison et al., 2006), ideally people should seek counselling on their own volition when they realize that the problems they have is beyond their own control (Sue \& Sue, 2013). However, even with students seeking counseling process, it is not something everyone can do because it depends on personality. Regarding personality, research has shown that extroverts are most likely to respond positively to counselling as they are easily able to articulate their concerns to the counselor as opposed to introverts who are reserved (Dryden and Reeves, 2008).

Another integral component of diversity influencing people's response to counselling is culture. Culture is reflected in people's customs, traditions, taboos, morales that a particular population hails from. People, due to their contexts are likely to view counselling differently. Culture, therefore, is a phenomenon that determines how people think, behave and determine the do's and don'ts of their communities (Kang'ethe, 2009). To this end, literature indicates that some students perceive counseling to be linked to deficiency and stigma (Meiberg, Arjan, Bos , Hans, Onya and Herman,2008). Thus it may take very long to find a workable solution to the problem identified in such student's performance (Giovazolias, 2010).

For instance, in some contexts, someone should only seek help from someone who is older and of the same gender as the one seeking help. This means that peer counselling is not accepted in such contenxts. A study by Motsabi (1999) in one South African insitutions found that peer counselling was not used because students were not trusting the capacity of the peer counsellors to uphold intergrity. This was mainly because peers were believed to be inexperienced compared to elders who were believed to possess more wisdom.

Also, in some cultures, it is unacceptable to seek advice from anyone outside nuclear family or from just a stranger (Juma, 2011, Dryden \& Reeves, 2008). To this end, Juma (2011) argues that in most African cultures, seeking help is confined to elders in the community and close relations. Anyone who attempts to seek help outside this circle is seen as exposing oneself to the public. Therefore, students who come from communities with such beliefs are unlikely to seek counseling services from professional counselors because they regard them as strangers. This is exacerbated by contexts where the counselor-student ratios are so high that there is minimum opportunities for counselors to develop close relationships with students. This study, therefore, explores which aspects of culture deter students from using counseling services in their campuses.

Pivotally, one aspect of culture that may influence counseling process is language. Since counseling involves several meetings with counselor to discuss issues of concern, clients who do not clearly understand the language used during the counseling sessions find it uncomfortable to discuss with counselor. To this end, Maree (2009) contends that psychometric testing instruments largely cater for communities who speak English as first language. In a multi-lingual country like South Africa, this scenario, therefore, segregates majority of the students whose first language is not necessarily English. Such students struggle to understand the questions asked during the psychometric testing exercise and this could produce unrealiable results. Therefore, language barrier can be one of the causes for negative attitudes towards counseling services and programmes.

It is in this lens that these researchers would like to explore why some students, despite facing problems that demand counseling, may shun the services altogether. This is to ensure that some aspects of culture that may be retrogressive towards the consumption of the services of higher learning are diluted; while at the same time work towards promoting aspects that are deemed progressive towards encouraging or enhancing learning. However, it is critical that the researchers are careful not to be biased while making interventions to people of diverse backgrounds and dispositions. Their stand and value should be critically respected.

\section{Methodology}

\subsection{Research Approach}

The study adopted a mixed method approach. This entailed using both quantitative and qualitative approaches to collect data. Johnston and Christensen (2012) highlight that the benefit of using multiple approaches is that data becomes more credible. 


\subsection{Research Design}

The study adopted concurrent mixed method triangulation design employing a mini survey and a case study (Teddlie \& Tashakkori, 2009).

\subsection{Sampling Frame}

The sampling frame composed all students registered in the two institutions under study constisting of about fourty thousand students.

\subsection{Unit of Analysis}

The sample consisted of 220 conveniently sampled first year students drawn from two former black universities .

\subsection{Sample selection and procedures}

The participants for the study were conveniently sampled from those enrolled in the first year of their study in the two institutions. First year students were an ideal sample because they are believed to encounter more transition challenges in higher education due to being in a new environment ( Kuh, 2008), hence have increased need for emotional support. Bojuwoye (2002) found that sources of stress for most first year students in South Africa emanated from financial difficulties, administrative processes during the initial months, workload and time management demands and relationships.

Also, most students in the first year of teir study still have close ties with their home communities, hence cultural beliefs and practices are still stronger than the senior students. Therefore, their views are pivotal in analyzing the effects of culture in counseling.

\subsection{Research Methods and Instruments}

Although the study used mixed methods, questionnaire interviews and some in-depth one-on-one interviews were used in tandem. While questionnaires were used to gather quantitative data from the first year students, an interview guide was used to gather data from the interviews and focus group discussions. Questionnaires are tools that gather large amounts of the data within a short period of time from a widely dispersed group of people (Johnson \& Christensen, 2012); while interview guides allows ample room for probing and therefore exhausting the participants views, opinions and thinking. Document analysis was also an important method that collected a lot of qualitative data.

\section{Research Domain}

The research domain was the two universities that had largely a rural population. The selection of the study domain was determined by many factors such proximity to the researcher, willingness to participate in the study and the existence of a functional student counseling program

\section{Ethical and Legal Considerations}

The researchers obtained permission to gain access to documents and to interact with the students. from the ethics committees. Each of the participants was also allowed to freely consent to participate in the study (Leedy, 2005). This was achieved though a letter explaining the purpose of the study and an accompanying consent form to confirm willingness to participate. The researchers upheld the confidentiality of participants by using anonymous codes and pseudonyms when presenting and reporting on the data (Silverman, 2010).

\section{Data Analysis and Interpretation}

Given that most of the data for this paper was quantitative, the data was analysed deductively. This means that emerging trends were presented in the form of tables to illustrate first year views about counselling. 


\section{Data Credibility and Trustworthiness}

Data credibility was achieved through a pilot study of the survey with 20 first years who did not participate in the final study. The pilot study helped to correct inconsistencies within the questionnaires (Teddlie \& Tashakori, 2009). The triangulation of methods also ensured that the weakness of one method was countered by other methods.

\section{Limitations of the Study}

The study only sought the views of first year students, but excluded most of the lecturers who sometimes provided referrals. Also the counselors' views were mainly derived from program reports. Therefore, there are ample possibilities that some insights in the reports could have changed over time.

\section{Data Presentation}

\subsection{Counselling addressed students' concerns}

In this study, first year student participants who used counselling services were also assisted on issues of mental health, career choices, finance and social issues. This implies that counselling is an important program for enhancing both academic and social integration as highlighted by Tinto 's (1993) theory on student retention. Despite its potential to improve psychological wellbeing of individuals by allowing them to reach their maximum developmental potential (Rogers, 1971), very few of the enrolled students actually make use of the counselling programmes on campus. However, cultural issues were suspected to be the possible cause.

\subsection{Students minimally used counselling service from teachers and professionals}

The study sought whom first year students consulted when experiencing challenges. Table 1 below validates that most students did not consult anyone and the few that sought help did so from family members and friends.

Table 1: Sources of first year students' counselling

\begin{tabular}{ccc}
\hline Counselling Assistance Sought & Total & Percentage \\
\hline None & 88 & $40 \%$ \\
Teacher & 22 & $10 \%$ \\
Peer Counsellors & 15 & $6.8 \%$ \\
Family & 70 & $31.7 \%$ \\
Friend & 25 & $11.3 \%$ \\
Total & 220 & $100 \%$ \\
\hline
\end{tabular}

The finding above show that the majority of the students did not make use of the counselling service available in their institution as $40 \%$ (88) of the students never consulted anyone when experiencing challenges. This is despite the fact that first year students are known to be usually experiencing myriad challenges due to being in a new environment which is sometimes different from their homes and previous schooling system. The results show that $70(31.7 \%)$ depended on the family, $15(6.8 \%)$ used mentors while $25(11.3 \%)$ made use of friends. The fact that most of the counselling help was sought from family members and other social networks is an indicator of the role of cultures and its determinant factors as important ingredients in determining the consumption of counseling services. The importance of a trusting relationship perhaps provided by cultural networks to be part of the counseling characteristic is therefore critical if counseling has to be successful. Table 2 below provides insights from students' views. 


\subsection{Students' cultural backgrounds viewed counseling as a service of the strangers.}

Table 2: Student Perceptions of Counseling

\begin{tabular}{lcc}
\hline Aspect & $\mathbf{N}=\mathbf{2 2 0}$ & Percentage \\
\hline Some counsellors/mentors are young and inexperienced & 30 & $17 \%$ \\
I don't trust advise from strangers & 80 & $36 \%$ \\
I don't need counselling because I can solve my own problems & 70 & $32 \%$ \\
I don't think my problem is so big to require counselling & 50 & $22 \%$ \\
\hline Total & $\mathbf{2 2 0}$ & $\mathbf{1 0 0 \%}$ \\
\hline
\end{tabular}

Table 2 above shows that the majority of the students were not seeking counselling because of various reasons such as ability to solve their own problems (32\%), counselors were too young (17\%), thinking that their problems did not require the services of counseling (22\%); and viewing counseling as a service offered by the strangers. While this response could imply having counseling as a problem solving skills, it could also mean a state of denial on the part of these students. Importantly, these researchers pin the role of students' cultural background as a critical contributory factor in viewing the counseling services as inadequate as it was discharged by the strangers. From a cultural perspective also, it is possible that such students believed that people who could not solve their own challenges are weak. This is also reflected in the following response from one of the students:

"People associate counselling as a service of people who have failed to handle their problems in life. So it's even frightening for people to mention that they are going for counselling".

The above responses find support from source literature that perceive counseling to be linked to deficiency may take very long to find a workable solution to their problems(Giovazolias, 2010).

\section{Discussion of the Findings}

While studies conducted in other South African higher education institutions attest that counselling provide support to students on a wide range of topics such as relationships, career selection, mental health and social problems that may hinder student success and retention (De Jager,Ntlokwana, 2012;Hartung, 2009, Maree, 2009), culture seem to inhibit or enable the use of counselling services (Maree, 2002, Norton, 2002). In this study, the fact that $35 \%$ (80) indicated that they could not share problems with anyone points to the belief that anyone who is not able to solve their own problem is weak. Such thinking, these researchers contend could emanate from the students belief systems which are embedded in their cultures. However, conceptualization of counselling could be influenced by the environment one grows which in turn influences how one perceives the world around them. This response not only shows these students' state of ignorance of the importance of professional counseling (Norton, 2002), but also points to the fact that despite accelerating high in the educational ladder, some of the cultural beliefs still influence how students behave in higher education environments . Similarly Giovazolias et al., (2010) found that both staff and students in Greece knew about the existenseof counselling and its importance, but were not using the service because of the negative perceptions students held about the counselling.

In some cultures especially from African origin, problem solving takes a clear gender dimension. It is not easy for problems to be solved across genders. In other words, men's problems should not be shared with women and vice versa. The fact that some students could not consult the younger counselors is an indicator of cultures as far as viewing advice or problem solving endeavours. Many cultures believe that younger people should seek words of advice, or counseling from the elderly. It is therefore fore not culturally appropriate for the elders to seek counseling from the younger. There is a belief is that young women ought to consult the elderly women in the same way as young men seek help from the elderly men. This means that help seeking endeavours in most cultures follow a distinct gender path. To this end, Juma (2011) found that the majority of the African students at one South African institution considered it unethical to seek help from someone of the opposite sex and someone younger. Instead, support was mainly solicited from family members and trusted elders in the community. This causes a dilemma to counselors because such individuals tend to shun any attempts to be counseled, even with aspects of their carreers and wellbeing. The dilemma occurs when such students are not able to obtain constructive support from their trusted social networks, many that are cultural in nature

In some societies especially in Africa, it is taboo to share one's problems with someone who does not belong to the same ethnic grouping as oneself. This is viewed as exposing oneself to the public. This view is also supported by findings 
in this study where $80(36 \%)$ of the students indicated that they do not seek advice from strangers. Such beliefs are still upheld in rural and township communities in most parts of Africa where tribal conflicts are still strong. This means that discussing one's problems with a stranger is uncommon and sometimes viewed as "washing one's dirty linen in public. This finding supports earlier observations at the University of Limpopo where 72 black undergraduate students between the ages of 18 and 32 years highlighted distrust of the health care workers who they believed were not skilled enough to administer adequate testing. Others feared that the health workers could disclose their status and would lower their opportunities for employment (Meiberg, Arjan, Bos , Hans, Onya and Herman, 2008).

Perhaps further research on unique features of counselling from an African perspective is required if the consumption and the intake of counseling services is to increase. This finding may therefore raise a need to put in place structures that mimic the family unit to ensure that more students make use of the service.

However, despite the fact that most of the students came from rural communities, one would expect the infiltration of westernization through the internet and other media to slowly erode people's beliefs, especially among those who dwell in urban areas where there is increased contact with professional counseling centres. It seems that this influence was probably not prominent because the majority of the students viewed counseling services negatively.

Incontrovertibly, human beings in general tend to seek assistance from the people they know and trust. Even in counseling programs, delivery is underpinned by principles of trust, confidentiality and genuinity of the counselor (Dryden \& Reeves, 2008; Feltham \& Horton, 2006). In this study, responses from the students also affirmed that besides cultural issues, trust was critical for students to embrace counseling. Some students opted to seek help from teachers and friends mainly due to the trusting relationships forged beforehand. This finding has implications on the selection of mentors and peer counselors who should assist students in higher education. Effort should be made to have students from various backgrounds so that students can associate freely to express their concerns. Also, there should be representativeness in terms of gender to allow both gender representations in counseling services.

As expounded above, the same view is also advanced by advocates of counseling who assert that trust is one of the necessary conditions for the success of the counseling process. However, the current study showed mixed results about students' use of counseling services. On one hand, a few students sought counseling because they were not confident of the professional skills of the counselors, some of whom were age mates or even younger. This finding also relates to a previous study at another former black university where peer counselling was not successful because of the stigma associated with the service as well as lack of trust and confidence with the peer counsellors (Motsabi, 1999). The counselor is required to have personal and professional qualities that dissipate fear from clients. For instance, counselors ought to be friendly, empathetic, upholding integrity, and non judgmental (Uys and Cameron, 2003). This is believed to enhance the counseling process (Morrison et al., 2006).

\section{Way Forward}

The study demonstrated that culture is a critical determinant of students' acceptance and consumption of counseling services. Therefore, it is important that counselling admistrators consider using culturally sensitive strategies when delivering the program. It may also be important for the the program to clearly specify how the cultural issues such as language, traditional beliefs are addressed in the program, so as to clarify expectations and possibly minimise client distrust. Apart from using pamphlets and posters and presentations at orientation forums as a way of marketing counselling programs, perhaps the use of movies depicting typical situations requiring counselling in the weekly orientation seminars or life skills courses might empower students on how to solve problems, and socialise them to realise that counselling is indeed an important educational endeavour.

Importantly, people who are given the role of counselling should posess personal and professional skills and qualities that commands trust and respect from their clients. This is because this study found that most of the students were questioning the professional intergrity of the counsellors. Also, given that social networks from trusted friends and relatives also proved to be a frequent source for counselling, institutions should continue to encourage parents to take an active role in supporting students. They may also be need to set up structures that mimic the family and community structures so as to assist students that do not get such emotional support from their homes.

Also, marketing of counselling programs should attempt to highlight well known negative cultural beliefs and pracices that disadvantage students' wellbeing so that students become aware of these. This is because at times people become too engrossed in their cultural values that sometimes fail to identify possible negative effects on their wellbeing. For example, students who would not seek help because of the belief that it's a sign of weakness need to be educated of the importance of social networks for healthy life. 


\section{Conclusion}

Pivotally, culture and its concomuitant dictates were found to be critical determinat of freshmen's capacity to cionsume counselling services in the two institutions of higher learning under the study. This made the clients not to trust the counsellors and by extension the services. This therefore points to the need to make counselling services to be culturaaly appropriate and friendly if the consumpotuion of counsellingservices are to increase. Perhaps factoring in the fact of cultural diversity such as gender and cultural backgrounds such as belief systems in counselling could help in making more clients access tye services. In order to eradicate negative cultural values and beliefs held by some students in relation to counselling, perhaps ongoing workshops and seminars can be infused into the curriculum to deal with such issues.

\section{References}

Astin, A.W., \& Oseguera,L. (2009). Precollege institutional influences on degree attainment.

Babbie, E. (2007). The Practice of Social Research (11th Edition ed.). Belmont: Thompson Wadsworth.

Bergman, M. (2008). Advances in Mixed Methods Research: Theories and Application. London : SAGE.

Bowman,B.\& Payne,J. (2011). A profile of students recieving counselling services at university in post apartheid South Africa. Journal of Chidl and Adolescent mental health , 143-153.

Creswell, J. (2009). Research Design: Qualitative, Quantitative and Mixed Methods Approches (3 ed.). Thousand Oak: SAGE.

Dryden,W.\& Reeves,W. (2008). Key Issues for Counselling in Action. Thousand Oaks: SAGE.

Drew, A. (2001). Students perceptions of what help them learn and develop in higher education. Teaching in Higher Education , 309331.

Drew, C.J.,Hardman,M.C.,\& Hoop, J.L. (2008). Designing and Conducting Research in Education. London: SAGE.

Ender, S.C. \& Newton,F.B. (2000). Students helping students: A guide for peer educators on college campuses: trainers guide. San Fransisco: Josey -Bass.

Feltham,C.,\& Horton, I. (2006). The SAGE handbook of Counselling and Pyschotherapy. Thousand Oaks: SAGE.

Giovazolias, M.J., Leontopoulou, S \&Trivia,S. (2010). Assessment of Greek students counselling needs and attitudes. International Journal for the Advancement of Counselling , 32, 101-116.

Johnson, B. \& Christensen, L. (2012). Educational Research: Quantitiative, Qualitative and Mixed Approaches. (4th Edition ed.). Far East Square: SAGE Publications.

Juma, J.O. (2011). African Worldviews: their impact on psychotherapy and psychological counseling. Masters in Psychology. UNISA.

Kang'ethe, S.M. (2009). Inadequate male involvement in health issues: the cause of gender skewed HIV and AIDS situations in Botswana. In: Maundeni T, Osei Hwedie BZ, Mukaamambo E, Ntseane PG (eds.) Male involvement in sexual and reproductive health: prevention of violence and HIVIAIDS in Botswana. Cape Town: Made Plain Communications, 7-28.

Kuh, G. D. (2008). High impact practices. What are they, who has access to them and why they matter. Washington, D.C: Association of American Colleges and Universities.

Leedy, P.O. (2005). Practical research planning and design. (8th Edition ed.). New Jersey: Pearson Prentice Hall.

Lundquist,C.,Spalding,R,J,Landrum,R,E. . (2003). College students thoughts about leaving university. The impact of faculty attitudes and behaviours. Journal College for Student Retention , 4 (2), 123-133.

Maree, J. (2009). Career Counselling in the 21st Centrury. South African institutions of higher learning at Cross Roads. South African Journal of Higher Education , 23 (3), 436-458.

Means, D. \& Thorne, B. (2007). Person-Centred Counselling in Action (2nd ed.). Thousand Oaks: SAGE.

BIBLIOGRAPHY V 7177 Miller M., \& Brown, S. (2005). Counselling for career choice: implications for improving interventions and working with diverse populations. In S.D Brown \& R.W. Lent: Putting theory and Research to work (pp 441-465). Hobiken, N J : Wiley \& Sons.

Modipane, M. (2011). Initial experiences of first entering students at the University of Limpopo: Implications for coping with studies. South African Journal on Higher Education , 25 (8), 1592-1607.

Morrison, M.J., Brad, H.V. \& Cilliers, C.D. (2006). Assessing the impact of student counselling services centres at tertiary education institutions. How shilud they be approached. South African Journal of higher Education, 20 (5), 655-678.

Motsabi, E. (1999). Peer counsellor utilisation in a South African tertiary institution. University of Johannesburg. Johannesburg: University of Johannesburg digital library.

North, P. (2002). Student under Stress- so why are they not queing for counselling. Association of University and College Counselling Journal (Special issue), 33-35.

Nicholas, M. (2002). South African first year students counselling needs and preferred counselling sources. International Journal of Advanced Counselling , 24, 289-295.

Rogers, C. (1971). Client Central Therapy. London.

Seitawan, J. (2006). Willingness to seek Counselling and Factors that facilitate and inhibit the seeking of Counselling in Indonesian undergraduate students. British Journal of Guidance and Counselling , 34 (3), 403-427.

Silverman, D. (2011). Qualitative Research:Issue of Theory Methods and Practice (3rd ed.). London: SAGE. 
Tashakkori, A. \&. Tashakori, A. (2009). Mixed methodology: Combining qualitative and quantitative approaches. Applied Social Research Methods Series (Vol. 46). Thousand Oaks, CA: SAGE Publications.

Woolfe, R. (1995). Students counselling in British univeristies: Issues and Challenges. International Journal for Advancment of Counselling , 18 (4), 223-233. 